\title{
Effects of Temperature on Ethylene-induced Phenylalanine Ammonia Lyase Activity and Russet Spotting in Harvested Iceberg Lettuce
}

\author{
M.A. Ritenour, M.J. Ahrens, and M.E. Saltveit ${ }^{1}$ \\ Department of Vegetable Crops, Mann Laboratory, University of California, Davis, CA 95616-8631
}

Additional index words. Lactuca sativa, postharvest disorders, PAL, secondary metabolism

\begin{abstract}
Experiments were conducted to study the effect of temperature on the ethylene inducibility of phenylalanine ammonia lyase (PAL, EC 4.3.1.5) activity and the development of russet spotting (RS) in Iceberg lettuce (Lactucu sutiva L.). Tissue exposed to ethylene and held at 15 or $20 \mathrm{C}$ showed earlier hut lower peaks in PAL activity than tissue held at $5 \mathrm{C}$. Accumulation of total soluble phenolic compounds, and the development of RS paralleled increases in PAL activity after a short lag period. Lettuce tissue transferred from 5 to $15 \mathrm{C}$ after 1 to 3 days showed later hut higher peaks in PAL activity than tissue continuously held at $15 \mathrm{C}$. Transferring ethylene-exposed tissue to $\mathrm{OC}$ before RS symptoms developed greatly limited further rise in PAL activity and RS development. Discontinuing ethylene exposure after 4 days resulted in a rapid decrease in PAL activity. Lettuce tissue exposed to ethylene for 4 days and then transferred from 5 to $0 \mathrm{C}$ after the development of moderate RS symptoms showed no difference in RS after 8 days compared to tissue stored continuously at $5 \mathrm{C}$.
\end{abstract}

Russet spotting (RS) is a major physiological disorder of harvested Iceberg lettuce. It is induced by exposure to ppm $\left(\mathrm{ml} \cdot\right.$ liter $\left.^{-1}\right)$ levels of ethylene and is most severe at temperatures around 5C (Rood, 1956). When exposed to $10 \mathrm{ppm}$ ethylene at 5C, symptoms appear after-3days and are characterized by the appearance of 1- to 2-mm-diameter oval brown sunken spots along the midrib, which in advanced stages may spread over the entire leaf blade (Link and Gardner, 19 19; Lipton, 1961; Rood, 1956). Storage at 0C almost completely inhibits RS development. Other factors affecting RS development are $\mathrm{O}_{2}$ concentration (low concentrations inhibit $\mathrm{RS}$ ), $\mathrm{CO}_{2}$ concentration (high concentrations inhibit RS), maturity (firmer heads are more susceptible), prior stress (physical injury exacerbates RS), and cultivar (e.g. 'Salinas' is more susceptible than 'Calmar') (Ke and Saltveit, 1988, 1989a; Morris et al., 1974; Rood, 1956).

Hyodo et al. (1978) observed that phenylalanine ammonia lyase (PAL) activity and phenolic compound content increased in lettuce tissue exposed to ethylene and that such increases correlated with increases in RS development. PAL catalyzes the deamination of L-phenylalanine to trans- cinnamic acid, which is the first committed step in the phenylpropanoid pathway, leading to the formation of secondary plant products (Camm and Towers, 1973; Kuoukol and Conn, 1961). Hyodo et al. (1978) also found that ethylene-induced PAL activity eventually decreased in tissue transferred from 5 to $12 \mathrm{C}$, while it continued to increase in tissue held at $5 \mathrm{C}$. This suggests that it may be possible to reduce PAL activity and subsequent RS by exposing tissue to elevated temperatures before visual symptoms of RS appear.

The present studies were undertaken to investigate temperature effects on the induction of PAL activity, the inactivation of PAL, and the subsequent development of RS in harvested Iceberg lettuce.

\section{Materials and Methods}

Commercially grown and harvested 'Salinas' Iceberg lettuce

Received for publication 4 Apr. 1994. Accepted for publication 28 July 1994. The cost of publishing this paper was defrayed in part by the payment of page charges. Under postal regulations, this paper therefore must be hereby marked advertisement solely to indicate this fact.

'To whom reprint requests should be addressed.
(Lactuca sativa L.) was purchased from a local wholesale market the day of harvest and transported to the Univ. of Calif. Davis Mann Laboratory where it was placed at $0 \mathrm{C}$. The following day, the lettuce was prepared and placed under the various treatments. Wrapper and cap leaves were discarded and the next 6 to 12 uninjured leaves were used. Because wounding induces PAL activity in tissue up to $2.5 \mathrm{~cm}$ away from the site of wounding and thus may enhance subsequent RS development (Ke and Saltveit, 1989b), we used whole leaves cut at their base and carefully separated from the head so that wounding (e.g., cracks, rips, etc.) did not occur within $3 \mathrm{~cm}$ of the tissue used for analysis. Excised leaves were placed in 20-liter jars and flows of humidified air $( \pm 10$ ppm ethylene were established at sufficient rates to maintain $\mathrm{CO}$, levels below $0.15 \%$. Two leaves were used for each replicate and each treatment had three replications. All experiments were repeated with similar results.

To test the effects of constant and changing temperatures on PAL activity, tissue was exposed to humidified air (210 ppm ethylene at $0,5,15$, and 20C. After 1 to 3 days, the tissue at $5 \mathrm{C}$ was transferred to 0,15 , or $20 \mathrm{C}$. During most experiments, ethylene treatments were maintained throughout the 8-day period. A temperature of $10 \mathrm{C}$ was not used because previous studies indicated that effects were intermediate between 5 and 15C (data not shown), and the observation of more pronounced effects were desired. Examination of RS symptoms, PAL activity, and soluble phenolic compound content occurred on day $0,2,4,6$, and 8 . In one set of experiments, $3 \times 4-\mathrm{cm}$ midrib segments were excised starting -3 $\mathrm{cm}$ from the midrib base, treated with ethylene at SC for 4 days, and transferred to air at 0,15 , or $20 \mathrm{C}$ for an additional 4 days.

Leaves were scored visually for RS symptoms using a scale of $1=$ no RS and $9=$ severe RS (Ke and Saltveit, 1986). These previous studies also showed that midrib segments are most sensitive to RS. Midrib segments, $3 \times 4 \mathrm{~cm}$ long, were excised from detached whole leaves starting $4 \mathrm{~cm}$ from the base and used for the analysis of PAL and phenolic compounds. PAL was assayed as described by Ke and Saltveit (1986). One unit of PAL activity equals the amount of PAL that produces $1 \mu \mathrm{mol}$ of cinnamic acid in $1 \mathrm{~h}$ under the specified conditions and is expressed as $\mu \mathrm{mol} / \mathrm{g}$ fresh weight per $h$. Total soluble phenolic compounds were extracted and measured using procedures described by Hyodo et al. (1978) using p-coumaric acid as the standard. Phenolic com- 
pounds are expressed as $\mu \mathrm{g} / \mathrm{g}$ fresh weight. Results were subjected to an analysis of variance, and when statistically significant differences were detected, LSD values were calculated at the 0.05 level.

\section{Results}

Exposure to $10 \mathrm{ppm}$ ethylene in air caused a rise in PAL activity at all temperatures (Fig. 1). PAL activity peaked in tissue held at 15 and 20C after 4 and 2 days, respectively, and then declined. Although PAL activity initially rose more slowly in leaves held at $5 \mathrm{C}$ than at 15 or $20 \mathrm{C}$ by day 6 PAL activity had risen above tissue held at 15 or $20 \mathrm{C}$, and was three times higher than either treatment by day 8 . In general, when the temperature was higher, the PAL activity peaked earlier, but this also created a smaller peak. For example, lettuce tissue held at 20,15, and 5C peaked after 2, 4, and ( $\geq 8$ days with levels of $0.18,0.22$, and 0.51 units of PAL activity, respectively. PAL activity slowly increased over 8 days at $0 \mathrm{C}$, surpassing on day 6 the declining activity in tissue held at 20C. After 6 days, tissue at 20C became unusable because of advanced senescence.

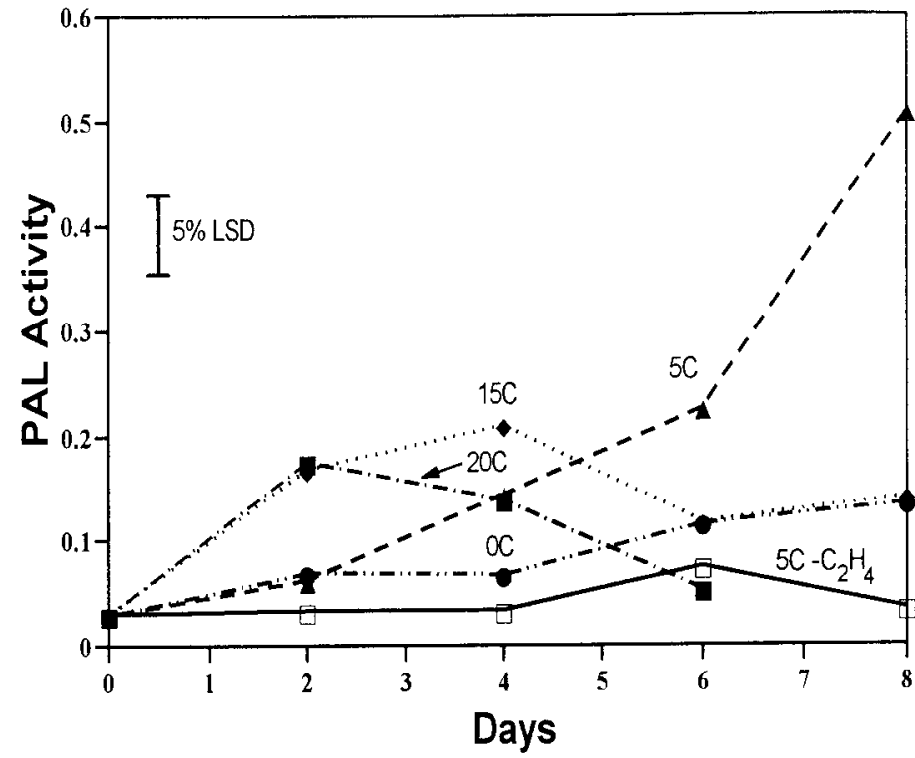

Fig. 1. Development of PAL activity in whole Iceberg lettuce leaves exposed continuously to air at $5 \mathrm{C}$ or to $10 \mathrm{ppm}$ ethylene at different temperatures. PAL activity is expressed as $\mu \mathrm{mol}$ cinnamic acid/g fresh weight per hour. The vertical bar represents the 5\% LSD value.

Continuous exposure to $10 \mathrm{ppm}$ ethylene at $15 \mathrm{C}$ resulted in a rapid increase in PAL activity which peaked after 2 days and then declined slowly (Fig. 2a). PAL activity in tissue transferred from 5 to $15 \mathrm{C}$ after 1 day lagged behind that of tissue held continuously at $15 \mathrm{C}$, but by day 4 , activity in the transferred tissue was greater than that in tissue held continuously at $15 \mathrm{C}$. PAL activity in tissue transferred after 3 days remained low for the first 2 days, then increased dramatically by day 4 . After 3 days at $15 \mathrm{C}$, PAL levels in tissue previously held at $5 \mathrm{C}$ for 3 days peaked at a level twice that of tissue held continuously at $15 \mathrm{C}$. Tissue not exposed to ethylene did not show any overall increase in PAL activity.

Total phenolic compound content and RS development (Figs. $2 \mathrm{~b}$ and $\mathrm{c}$ ) showed the same trends except that they lagged behind changes in PAL activity. For example, when tissue was transferred from 5 to $15 \mathrm{C}$ after 3 days, PAL activity rose above that of tissue continually held at $15 \mathrm{C}$ by day 4 . However, total soluble phenolic compounds content and RS development did not begin to rise above tissue continually held at $15 \mathrm{C}$ until day 6 . After 8 days of continuous ethylene exposure, RS development was significantly greater in tissue transferred to $15 \mathrm{C}$ after 3 days than tissue transferred after 1 day or held continuously at $5 \mathrm{C}$. As expected, tissue not exposed to ethylene showed no significant increase in total soluble phenolic compound accumulation and RS development during the 8 days.

Lettuce tissue held at $5 \mathrm{C}$ and then transferred to $0 \mathrm{C}$ after 1 to 3 days did not show significant differences $(0.05 \%$ level) in PAL activity from tissue continuously held at $0 \mathrm{C} \pm$ ethylene (data not shown). Low temperature suppresses the increase in induced PAL activity even after 3 days of optimal conditions (10 ppm ethylene at 5C). Tissue at $20 \mathrm{C}$ deteriorated rapidly and became unusable after $\approx 6$ days. There was a noticeable increase in the rate of deterioration in tissue exposed to ethylene compared to unexposed tissue especially at 15 and 20C (data not shown).

When treated with $10 \mathrm{ppm}$ ethylene throughout the experiment, PAL activity increased sharply and at the same rate 1 day after transfer to 15 and 20C following 3 days at 5C (Fig. 3a). Transfer-
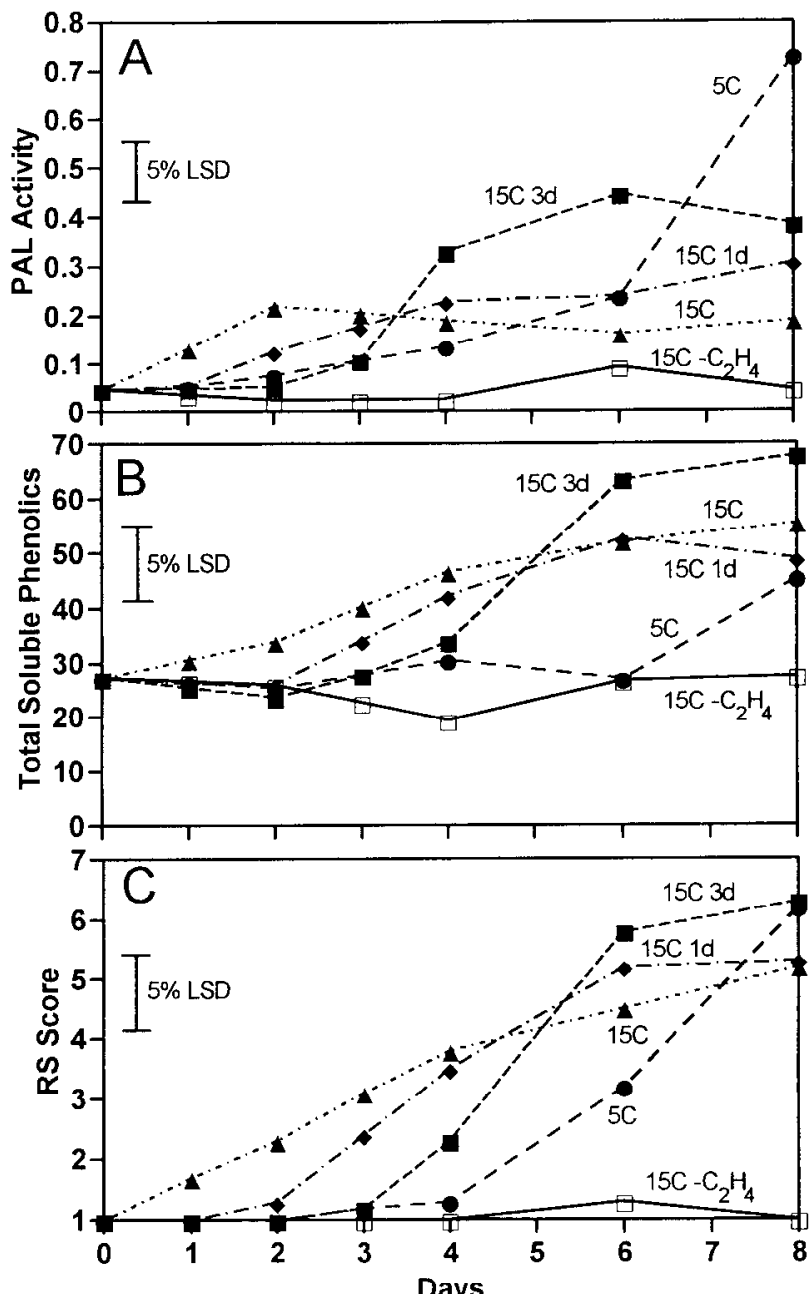

Fig. 2. PAL activity (A), total soluble phenolics content (B), and RS development (C) in whole Iceberg lettuce leaves continuously exposed to $10 \mathrm{ppm}$ ethylene in air. Leaves were stored at $5 \mathrm{C}$ for 1 to 3 days before being transferred to $15 \mathrm{C}$. Continuous storage at $15 \mathrm{C}( \pm 10 \mathrm{ppm}$ ethylene served as controls. Leaves held at the optimal RS inducing conditions of 5C plus $10 \mathrm{ppm}$ ethylene are included for comparison. PAL activity is expressed as $\mu \mathrm{mol}$ cinnamic acid $/ \mathrm{g}$ fresh weight per h. Phenolic compounds are expressed as $\mu \mathrm{g} / \mathrm{g}$ fresh weight. Leaves were scored visually for RS using a scale of $1=$ no RS, and $9=$ severe RS. The vertical bar represents the $5 \%$ LSD value. 

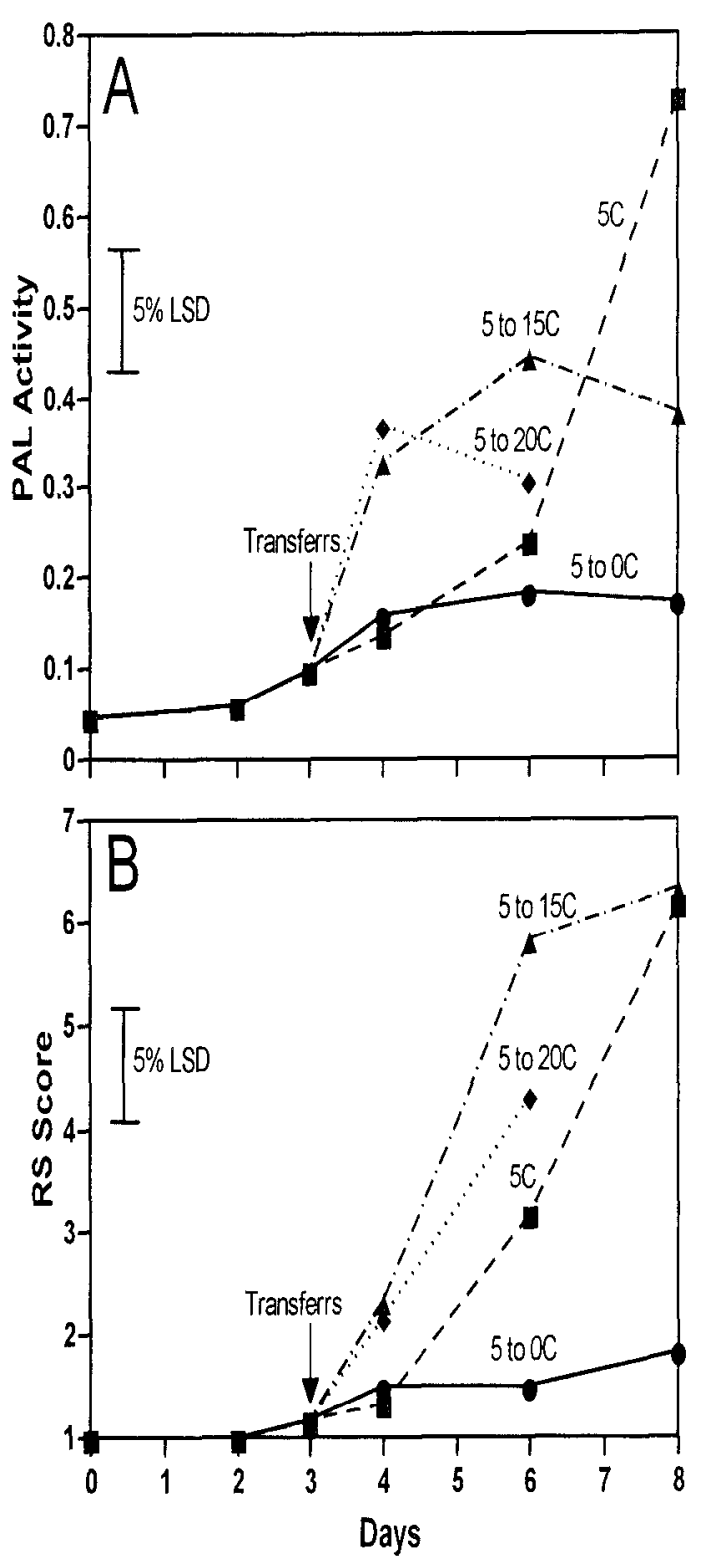

Fig. 3. PAL activity (A) and RS development (B) in whole Iceberg lettuce leaves transferred to 0,15 , or $20 \mathrm{C}$ after 3 days at $5 \mathrm{C}$. Ethylene at $10 \mathrm{ppm}$ was maintained throughout the experiment. RS scored as in Fig. 2. PAL activity is expressed as $\mu$ mol cinnamic acid/g fresh weight per $h$. The vertical bar represents the $5 \%$ LSD value.

ring tissue to 15 and $20 \mathrm{C}$ caused a 0.22 and 0.26 unit rise in PAL activity, respectively, 1 day after transfer, while tissue remaining at $5 \mathrm{C}$ only had a 0.03 unit rise. PAL activity in tissue transferred to $0 \mathrm{C}$ increased at about the same rate as tissue kept at $5 \mathrm{C} 1$ day following transfer but leveled out during the rest of the experiment. After day 4, PAL activity in tissue transferred to $20 \mathrm{C}$ began to decrease while activity in tissue at $15 \mathrm{C}$ continued to increase, albeit at a much slower rate. Activity in tissue held at $5 \mathrm{C}$ continued to rise at an increasing rate and was almost twice the PAL activity of the next highest treatment by day 8 . Tissue transferred from 5C to 15 and $20 \mathrm{C}$ after 3 days showed the largest increase in RS development 1 day after transfer, while tissue transferred to $0 \mathrm{C}$ or held at 5C did not increase significantly over the same period (Fig. $3 \mathrm{~b})$. Corresponding to the drop in PAL activity on day 6 , RS development in tissue transferred to 20C did not keep pace with that of tissue transferred to $15 \mathrm{C}$, whose rate of PAL activity was still increasing. After day 6, the rate of RS development declined in tissue transferred to $15 \mathrm{C}$. Tissue at $0 \mathrm{C}$ did not develop significant RS, while RS in tissue held at $5 \mathrm{C}$ continued to increase through day 8 . At the end of the experiment, RS development in tissue at 5 and $15 \mathrm{C}$ was equal. The rate of RS development, however, was still increasing in tissue at $5 \mathrm{C}$, while it was decreasing in tissue at $15 \mathrm{C}$.

Midrib segments exposed to $10 \mathrm{ppm}$ ethylene at $5 \mathrm{C}$ for 4 days and then transferred to air at different temperatures exhibited rapid decreases in PAL activity 2 days after transfer (Fig. 4a). Even after continuous storage at the optimum RS-inducing temperature of $5 \mathrm{C}$, PAL activity dropped to $\approx 30 \%$ of its maximum value 2 days after ethylene removal. PAL activity dropped to baseline levels in tissue transferred to either 15 or 20C 2 days after ethylene was removed, but decreased more slowly in tissue transferred to $0 \mathrm{C}$. There was no significant difference in RS development among ethylene treated tissues over the 8 day experiment (Fig. 4b). RS development continued until day 6 in all ethylene treated tissue before leveling off.

\section{Discussion}

Tissue exposed to $10 \mathrm{ppm}$ ethylene at 15 or $20 \mathrm{C}$ had depressed maximal levels of PAL activity compared to lettuce tissue exposed to ethylene at 5C (Fig. 1). At 0C, PAL activity rose slowly over the 8 day period. In addition, tissue placed at 15 or 20C not only showed a more rapid increase in PAL activity, but also showed a more rapid loss of PAL activity, which prevented its activity from rising to a level as high as $5 \mathrm{C}$. Total PAL activity is regulated by the rates of the separate processes of synthesis and inactivation. Zucker (1970) showed that when Xanthium leaf discs were placed in darkness after PAL activity had been induced by exposure to light, PAL activity decreased sharply while PAL synthesis continued unabated. Hyodo et al. (1978) suggested that an unidentified PAL inactivator could be responsible for the decreases in PAL activity in lettuce tissue.

Tissue exposed to ethylene and transferred from 5 to $15 \mathrm{C}$ after 3 days showed a greater but delayed peak in PAL activity compared to tissue transferred after only 1 day (Fig 2a). For example, delaying the transfer to $15 \mathrm{C}$ from 1 to 3 days delayed the peak in PAL activity from 2 to 6 days but doubled the maximum levels of activity. However, the maximum level of PAL activity in tissue transferred after 3 days was still less than half that of tissue held at 5C after 8 days (Figs. 1 and 2a). Thus, it appears that the processes leading to an increase in PAL activity (e.g., transcription, translation, and any subsequent protein modifications/activations) occurs more rapidly at elevated temperatures. The initial rise in ethyleneinduced PAL activity is probably due to the de novo enzyme synthesis, rather than an activation of bound or otherwise inactive PAL protein precursors. Ke and Saltveit (1989b) found that treating wounded tissue with transcription or translation inhibitors prevented increases in wound-induced PAL activity. However, there may be an accumulation of PAL mRNA and/or inactive PAL in tissue induced by exposure to ethylene at $5 \mathrm{C}$ which is rapidly used in synthesis or conversion to an active form when the tissue is transferred to higher temperatures. Accumulation of a precursor is supported by the observation that PAL activity increased 0.09 units per day in tissue continuously treated with ethylene at $15 \mathrm{C}$, while it increased 0.22 units per day in tissue transferred to $15 \mathrm{C}$ after 3 days at $5 \mathrm{C}$ (Fig. 2).

After a short lag, total soluble phenolic compound content and RS symptom development generally paralleled PAL activity in lettuce tissue (Fig. 2). This data supports the hypothesis that PAL induction is a limiting step in RS development. However, Ke and 
Saltveit (1989c) showed that wounding induces PAL activity but not RS development. Thus, there appears to be another step, which subsequently becomes rate limiting and is more specific for RS development. At all temperatures, RS symptoms continued to increase in tissue exposed to ethylene during the 8 day experiment (Fig. 2c). This suggests that even though PAL activity peaked before maximum expression of RS symptoms, the remaining level of PAL activity, or phenolic compound content of the tissue, was sufficient to support continued RS development during the remaining period of time.

As was observed with Iceberg lettuce tissue continuously exposed to ethylene at 15 or 20C (Fig. 1), transfer of tissue to 15 or $20 \mathrm{C}$ after 3 days also induced earlier but lower peaks in PAL activity (Fig. 3a). Tissue transferred to 20C deteriorated after only 6 days (Figs. 1 and 3). Storage at 0C effectively retarded development of PAL activity and RS symptoms, even in tissue that was previously exposed to ethylene at 5C for 3 days (Fig. 3). Thus, even though PAL precursors appear to be available after 3 days at $5 \mathrm{C}$, transfer to $\mathrm{OC}$ effectively slows further increases in PAL activity
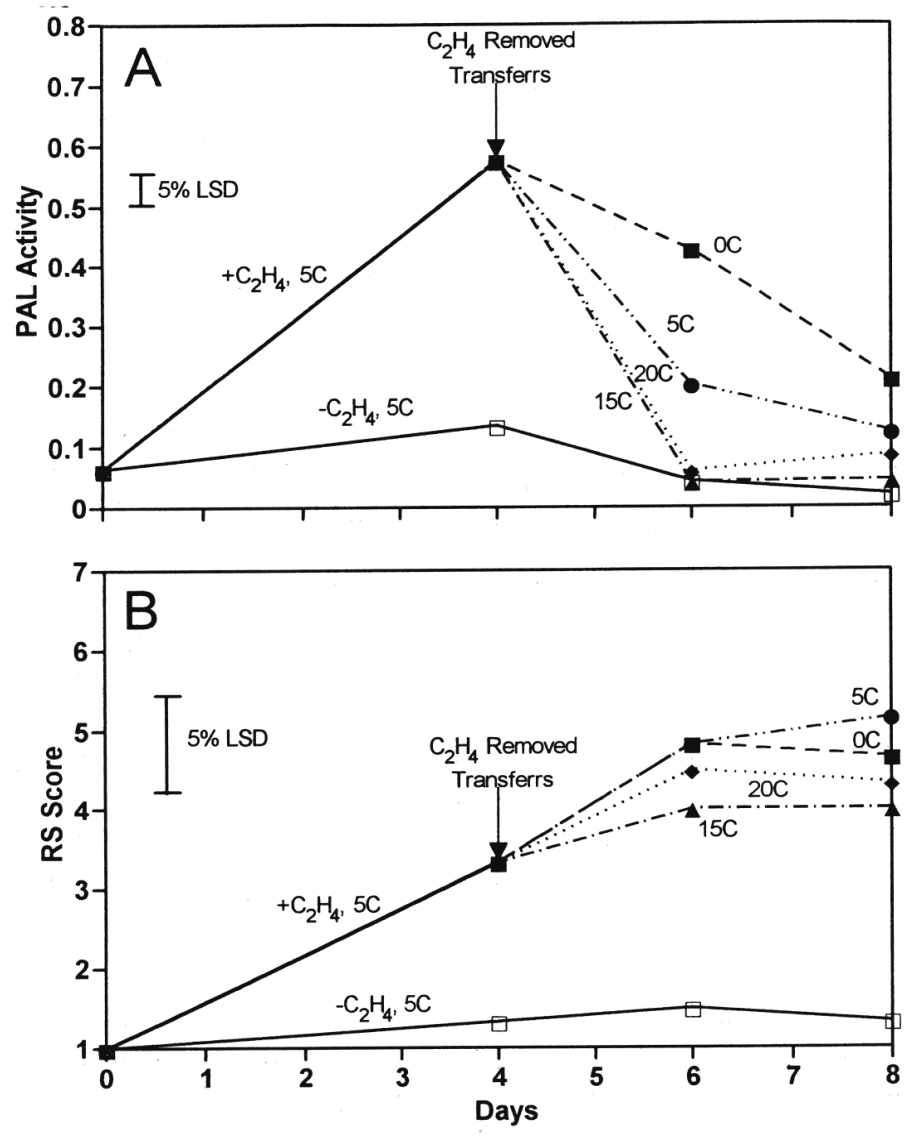

Fig. 4. PAL activity (A) and RS development (B) in midrib segments of Iceberg lettuce. PAL activity is expressed as $\mu$ mol cinnamic acid/g fresh weight per $h$. The vertical bar represents the $5 \%$ LSD value. and RS development. This emphasizes the importance of maintaining transit and storage temperatures for Iceberg lettuce as near $0 \mathrm{C}$ as possible. Even if the lettuce is allowed to warm to over 5C and is exposed to ethylene, quickly cooling to $0 \mathrm{C}$ before $\mathrm{RS}$ symptoms appear can prevent RS from developing. Transferring lettuce tissue to $15 \mathrm{C}$ after 3 days did not decrease the amount of RS development below that of tissue stored at $5 \mathrm{C}$ after 8 days but may have eventually result in lower RS development after 9 or 10 days (Fig. 3b). However, at higher temperatures the tissue 'aged' faster and would not last longer than 8 days before deteriorating to unacceptable levels.

PAL activity decreased in Iceberg lettuce tissue soon after ethylene was removed from the environment (Fig. 4a). Instead of observing a pronounced increase in PAL activity in tissue transferred from 5 to 15 or 20C (Figs. 1 and 3a), the tissue lost PAL activity more rapidly than tissue continually held at $5 \mathrm{C}$. Ethylene exposure is required for the continued synthesis of PAL to proceed more rapidly than its inactivation. Wounding during initial preparation of the midrib segments and 4 days of ethylene exposure had already caused RS symptoms to develop to moderate levels by day 4 so that transferring the tissue to $0 \mathrm{C}$ did not significantly reduce RS development. Thus, once RS symptoms appear, transferring to OC will not reduce final RS development even if further ethylene exposure is prevented.

\section{Literature Cited}

Camm, E.L. and G.H.N. Towers. 1973. Phenylalanine ammonia lyase. Phytochemistry 12:961-973.

Hyodo, H., H. Kuroda, and S.F. Yang. 1978. Induction of phenylalanine ammonia-lyase and increase in phenolics in lettuce leaves in relation to the development of russet spotting by ethylene. Plant Physiol. 62:31-35.

Ke, D. and M.E. Saltveit. 1986. Effects of calcium and auxin on russet spotting and phenylalanine ammonia-lyase activity in iceberg lettuce. HortScience 21:1169-1171.

Ke, D. and M.E. Saltveit. 1988. Plant hormone interaction and phenolic metabolism in the regulation of russet spotting in iceberg lettuce. Plant Physiol. 88:1136-1140.

Ke, D. and M.E. Saltveit. 1989a. Regulation of russet spotting, phenolic metabolism, and IAA oxidase by low oxygen in iceberg lettuce. J. Amer. Soc. Hort. Sci. 114:638-642.

Ke, D. and M.E. Saltveit. 1989b. Wound-induced ethylene production, phenolic metabolism and susceptibility to russet spotting in iceberg lettuce. Physiol. Plant. 76:412-418.

Koukol, J. and E.E. Corm. 1961. The Metabolism of aromatic compounds in higher plants. IV. Purification and properties of the phenylalanine deaminase of Hordeum vulgare. J. Biol. Chem. 236(10):2692-2698.

Link, G.E. and M.W. Gardner. 1919. Market disease of vegetables. Phytopathology 9:497-520.

Lipton, W.J. 1961. Anatomical observations on russet spotting and pink rib of lettuce. Proc. Amer. Soc. Hort. Sci. 78:367-374.

Morris, L.L., J.A. Klaustetmeyer, and A.A. Kader. 1974. Postharvest requirements of lettuce to control physiological disorders. Proc. 26th Intl. Conf. Handling Perishable Agr. Commission. p. 22-29.

Rood, P. 1956. Relation of ethylene and postharvest temperature to brown spot of lettuce. J. Amer. Soc. Hort. Sci. 68:296-303.

Zucker, M. 1970. Rate of phenylalanine ammonia-lyase synthesis in darkness. Biochim. Biophys. Acta 208:331-333. 